\title{
As crenças de universitários formandos de um curso de Educação Física - bacharelado, sobre o ensino dos esportes
}

\author{
Valmor Ramos \\ Jeferson Rodrigues de Souza ${ }^{2}$ \\ Vinícius Zeilmann Brasil ${ }^{3}$ \\ Ana Flávia Backes 4 \\ Matheus da Lapa Costa ${ }^{5}$ \\ Filipy Kuhno
}

\section{RESUMO}

O objetivo foi analisar as crenças de universitários do último ano de curso de graduação em Educação Física - Bacharelado, sobre os conteúdos e estratégias de ensino dos esportes. Realizou-se pesquisa qualitativa, com estudo de casos múltiplos de 5 universitários. A coleta dos dados ocorreu através de roteiros de entrevista semiestruturada e procedimento de estimulação de memória. Os dados foram analisados através de

1 Doutor em Ciência do Desporto. Professor da Universidade do Estado de Santa Catarina (UDESC/CEFID). Florianópolis/Santa Catarina, Brasil. E-mail: valmor.ramos@udesc.br

2 Mestre em Educação Física. Doutorando em Educação Física no Programa de Pós-Graduação em Educação Física da Universidade Federal de Santa Catarina (PPGEF/UFSC). Florianópolis/Santa Catarina, Brasil.

E-mail: jefersonrsouza@hotmail.com

3 Mestre em Educação Física. Doutorando em Educação Física no Programa de Pós-Graduação em Educação Física da Universidade Federal de Santa Catarina (PPGEF/UFSC). Florianópolis/Santa Catarina, Brasil.

E-mail: vzbrasil@hotmail.com

4 Graduação em Educação Física. Mestranda em Educação Física no Programa de Pós-Graduação em Educação Física da Universidade Federal de Santa Catarina (PPGEF/UFSC). Florianópolis/Santa Catarina, Brasil. E-mail: anafbackes@hotmail.com

5 Graduando em Educação Física na Universidade do Estado de Santa Catarina (UDESC/CEFID). Florianópolis/ Santa Catarina, Brasil. E-mail: matheusdalapacosta@gmail.com

6 Mestre em Ciências do Movimento Humano. Doutorando em Educação Física no Programa de Pós-Graduação em Educação Física da Universidade Federal de Santa Catarina (PPGEF/UFSC). Florianópolis/Santa Catarina, Brasil. E-mail: filipykuhn@hotmail.com 
análise de conteúdo, com categorias estabelecidas a priori. Os resultados indicaram que algumas crenças permaneceram estáveis ao fim do curso: A aula deve ser motivadora; a fragmentação dos conteúdos facilita a aprendizagem; as tarefas sintéticas são motivadoras; os conteúdos técnicos são essenciais para o esporte. Surgiram novos entendimentos sobre a utilização das tarefas sintéticas e o uso das formas jogadas. Conclui-se que as experiências diretas de prática de ensino e o engajamento dos sujeitos em contexto formal, foram fontes importantes de aprendizagens sobre como ensinar.

Palavras-chave: Educação física. Esporte. Crenças. Ensino. Formação inicial

\title{
Physical education preservice teachers' beliefs on sports teaching
}

\begin{abstract}
The purpose of this study was to analyze the physical education preservice teachers' beliefs on sports teaching content and tasks. A multiple case studiy took place with five preservice teachers'. The data were obtained through a semi-structured interview and memory stimulation procedures. Data were analyzed using the content analysis technique. The results showed that some beliefs remained stable at the end of the course: that class must be motivating; the fragmentation of content facilitates the learning; synthetic tasks are motivational; the technical content is essential for sport learning. Emerged other understandings about the use of synthetic tasks and play procedures. It's concluded that preservice teachers' direct experiences of teaching in a formal context and engagement of them in this context were most important sources to construct beliefs on teaching.
\end{abstract}

Keywords: Physical education. Sport. Beliefs. Teaching. Teacher education

\section{Las creencias de universitarios en Educación Física sobre la enseñanza de los deportes}

\section{RESUMÉN}

El objetivo de este estudio fue analizar las creencias de universitarios en Educación Física, sobre los contenidos e estrategias para enseñanza de los deportes. Se realizó una investigación cualitativa, con estudio de casos múltiples de 5 universitarios. Los datos fueran obtenidos por medio de entrevista semiestructurada y procedimiento de estimulación de memoria. Los datos fueran analizados mediante análisis de contenido, con categorías establecidas a priori. Los resultados indicaron que algunas creencias permanecieron estables al final del curso: la clase debe ser motivadora; la fragmentación de los contenidos facilita el aprendizaje; tareas sintéticas son motivadoras; los contenidos técnicos son esenciales para aprender el deporte. Surgieran nuevas comprensiones sobre la aplicación de tareas sintéticas y de las formas jugadas. Se concluyó que la experiencia en prácticas docente y la participación de los universitarios en contexto formal, fueron las principales fuentes de aprendizaje acerca de cómo enseñar.

Palabras clave: Educación física. Deporte. Creencias. Enseñanza. Formación del profesorado 


\section{INTRODUÇÃO}

Ao longo da vida as pessoas experimentam uma diversidade de situações sendo que algumas das experiências acabam se convertendo em informações singulares importantes, devido aos significados pessoais que lhes são atribuídos. Estas informações são armazenadas na memória sob a forma de esquemas psicológicos ou crenças, nas quais as pessoas se baseiam para guiar suas ações. Diferentemente do conhecimento, as crenças são individuais e não possuem garantia epistemológica de sua validade (RICHARDSON, 2003).

A perspectiva de que um novo conhecimento só pode ser construído sobre uma base de experiências e crenças prévias tem influenciado na forma como os professores têm abordado os processos de aprendizagem dos seus alunos (ABELSON, 1992; BEHETS; VERGAUWEN, 2006). Na formação inicial, as crenças são consideradas filtros mentais que condicionam os direcionamentos das aprendizagens dos universitários ao longo do curso (MATANIN; COLLIER, 2003; RICHARDSON, 2003). As propostas dos programas de formação, a partir desta perspectiva, é de estabelecer procedimentos sistemáticos que levem os universitários a refletirem sobre suas crenças, compreendê-las, e assim, aumentarem o engajamento em seus próprios processos de aprendizagem (FIVES; BUEHL, 2012; TSANGARIDOU; POLEMITOU, 2015).

Assim, as pesquisas no âmbito do pensamento do professor têm sido conduzidas no sentido de examinar a biografia de futuros professores, identificar a variedade de crenças que possuem, criando possibilidades para diagnosticar, acompanhar e orientar aprendizagens de novos conhecimentos ao longo do processo de formação profissional (MATANIN; COLLIER, 2003). De modo geral, as investigações são realizadas a partir de procedimentos qualitativos de pesquisa, com o objetivo de analisar as crenças sobre os propósitos e metas curriculares, conforme Randall e Maeda (2010), Kulinna et al. (2010), Philpot e Smith (2011), Sofo et al. (2012), Adamakis e Zounhia (2016), e, também voltadas a analisar as crenças sobre procedimentos de ensino e aprendizagem, conforme, Matanin e Collier (2003), Tsangaridou (2008), Bernstein, Herman e Lysniak (2013), Tannehill e MacPhail (2014).

Na formação inicial em Educação Física os resultados das investigações indicam que os universitários ingressam nos cursos com uma gama variada de crenças sobre como ensinar, provenientes das experiências esportivas na escola, as quais se baseiam em julgamentos pessoais, sendo algumas mais estáveis, e que podem ser aperfeiçoadas e até abandonadas. As crenças prévias dos universitários são persistentes porque o tempo de curso e as estratégias de formação são insuficientes e inadequadas para proporcionar as devidas mudanças (TSANGARIDOU, 2006).

Levando em consideração as mudanças conceituais a respeito da aprendizagem e as implicações das crenças pessoais no processo de formação inicial, o objetivo deste estudo é analisar as crenças de 5 graduandos em Educação Fisica do último ano do curso, a respeito dos conteúdos e estratégias de ensino dos esportes. Este estudo compõe uma pesquisa realizada, com os mesmos sujeitos, em duas etapas da formação inicial: 1) na primeira etapa, o objetivo foi identificar as crenças dos universitários, ao ingressarem na 
universidade; 2) na segunda etapa, o objetivo foi examinar a manutenção e/ou alteração dessas crenças ao final do curso. Este estudo que se apresenta, portanto, corresponde à segunda etapa

\section{MATERIAL E MÉTODOS}

A partir da abordagem de pesquisa qualitativa, de caráter descritivo e interpretativo (DENZIN; LINCOLN, 2008), foram investigados 5 universitários de graduação em Educação Física - Bacharelado de uma universidade pública no sul do Brasil (4 do sexo masculino e 1 do sexo feminino), em duas etapas na formação inicial. Na primeira etapa da pesquisa (primeiro ano de curso) os sujeitos estavam com idades entre 18 e 21 anos, e na segunda etapa, estavam com idades entre 22 e 25 anos. Para a seleção dos participantes, na primeira etapa, foram estabelecidos os seguintes critérios: a) estar cursando o primeiro ano de Graduação em Educação Física; b) estar cursando uma disciplina obrigatória, de caráter teórico-prático voltada ao processo de iniciação esportiva; c) não possuir experiência de atuação no ensino da Educação Física e esportes; d) expressar motivação e disponibilidade para participar do estudo. Para a segunda etapa: a) ter participado da primeira etapa da pesquisa; b) estar cursando o último semestre do curso de graduação; c) expressar motivação e disponibilidade para participar do estudo.

A coleta de dados, referente à primeira etapa da pesquisa está descrita detalhadamente em Ramos et al. (2014). Resumidamente, realizou-se os seguintes procedimentos: a) aplicação de roteiro com perguntas fechadas para selecionar os participantes; b) cada graduando selecionado elaborou um planejamento; c) cada participante realizou uma aula prática de ensino; d) gravação audiovisual de cada aula, através de câmera digital; e) análise de cada aula, quanto ao tipo de tarefas de aprendizagem, conteúdos e estrutura; f) realização de entrevista semiestruturada sobre biografia dos graduandos; g) realização de procedimentos de estimulação de memória, na qual uma entrevista semiestruturada foi realizada individualmente; h) as respostas da entrevista foram gravadas e transcritas literalmente.

A segunda etapa da pesquisa foi realizada no último semestre do curso de graduação e consistiu na aplicação de procedimentos de estimulação de memória semelhantes à primeira etapa: a) cada aula gravada na primeira etapa da pesquisa foi exibida novamente para cada sujeito, individualmente, por meio de microcomputador; b) simultaneamente à exibição, foi aplicado um roteiro de entrevista semiestruturada a respeito das ações pedagógicas adotadas em sua aula, relativamente às estratégias de ensino, aos conteúdos e à estrutura da aula; c) não houve qualquer menção aos resultados ou conclusões da primeira etapa, aos sujeitos. Na entrevista foram contempladas questões sobre: 1) se o graduando se reconhece e recorda da aula em tela; 2) se, na atualidade alteraria os procedimentos de ensino que utilizou nesta aula em tela; 3) quais alterações realizaria; 4) qual sua justificativa pessoal para a manutenção ou alteração; 5) quais as fontes de conhecimento nas quais se baseia seus entendimentos atuais. As respostas das entrevistas foram captadas através de gravador digital e transcritas literalmente por meio do editor de texto. A pesquisa foi 
aprovada por comitê de ética em pesquisa de uma universidade pública no Brasil, processo $n^{\circ} 83238 / 2012$. Todos os participantes assinaram o termo de consentimento livre e esclarecido e, para preservar o anonimato dos mesmos, cada um deles está identificado no texto por letras e números (S1, S2, S3, S4 e S5).

A técnica de análise de conteúdo foi utilizada com o objetivo de organizar os dados contidos nas imagens e transcrições, e também, para identificar os significados implícitos nas informações dos sujeitos, conforme sugere Bardin (2010). Os dados analisados foram as ações pedagógicas dos graduandos nas aulas gravadas na primeira etapa, e os dados obtidos por meio das entrevistas semiestruturadas realizadas na segunda etapa. As informações de ambas as fontes foram constantemente confrontadas e interpretadas pelo pesquisador, com o propósito de identificar pontos comuns ou divergentes, que pudessem caracterizar alguma mudança na forma de entendimento ou crenças dos graduandos, a respeito dos mesmos temas investigados (estratégias e conteúdos). Para a classificação dos dados utilizou-se categorias determinadas a priori, especificamente, o conhecimento curricular do conteúdo e conhecimento das estratégias baseado no modelo do conhecimento profissional de Grossman (1990), bem como as tipologias das tarefas de aprendizagem de Ticó-Camí (2002), e as condições de tarefas de aprendizagem conforme o modelo de progressão de Rink (1993). A validade descritiva e interpretativa dos dados foi obtida por meio de procedimentos de checagem pelos participantes, que consistiu no envio das descrições e interpretações aos graduandos para confirmação da veracidade das informações registradas pelo investigador; realizaram-se também descrições detalhadas dos procedimentos adotados no estudo (ALVES, 2002; ALVES-MAZZOTTI; GEWANDSZNADJER, 2004).

\section{RESULTADOS E DISCUSSÃO}

\section{As crenças a respeito das estratégias de ensino dos esportes}

A análise das crenças em momentos específicos da formação inicial pode se converter em um elemento limitador para a pesquisa, à medida que o estudo não analisa o processo contínuo de mudanças dessas crenças, ocorridos ao longo dos quatro anos de curso. Ainda, elas não representam a totalidade das crenças que os sujeitos possuem. Os resultados são, portanto, etapas das trajetórias individuais dos sujeitos, ao início e ao final da formação inicial. Acredita-se que a obtenção de dados, a partir de procedimentos sistemáticos de pesquisa, ao longo de todo o curso, poderá criar possibilidades para se identificar o processo gradual de mudança nas crenças dos sujeitos, bem como compreender os intervenientes do contexto da formação inicial na aprendizagem profissional. Desse modo, os dados apresentados neste texto estão delimitados, especificamente, as declarações mais atuais dos sujeitos a respeito da manutenção ou alteração das suas próprias crenças sobre o ensino dos esportes.

Assim, ao observar as imagens da aula gravada na primeira etapa do estudo e, ao ser questionado se adotaria as mesmas estratégias de ensino nos dias atuais, S1 indica que 
utilizaria tarefas que ele considera "mais abertas" ou do tipo "global", evitando a "especialização" e o caráter "mecânico" que as tarefas do tipo analíticas conferem ao ensino da técnica do futebol. No seu entendimento atual, a técnica deve ser ensinada de maneira combinada com outros fundamentos técnicos, através de formas jogadas, favorecendo a motivação e evitando o abandono da prática esportiva, em especial nos primeiros momentos de um processo de iniciação esportiva. Sua nova perspectiva seria priorizar atividades, por exemplo, de dois contra dois e jogo formal, enfatizando sobretudo, o lúdico e aprendizagens dos aspectos coletivos (táticos) inerentes ao jogo.

“Numa questão, principalmente de iniciação esportiva, eu faria primeiramente as-
sim um apanhado mais geral, assim global de todas as habilidades, trabalhando os
jogos. Então, trabalho muito em cima da questão do lúdico, trabalhando os jogos
em cima disso, pequenos jogos, grandes jogos, número reduzido de pessoas num
lado ou no outro, variações e, trabalhando todas as habilidades, todas juntas den-
tro desses jogos. Trabalhando o passe já, trabalhando o drible, trabalhando já a
condução, domínio, o chute para depois ir, colocando ali entre os treinamentos,
exercícios mais analíticos, para justamente, ter uma melhora das técnicas [...]" (S1).

Com relação à organização dos conteúdos, S1 cita a contribuição de algumas disciplinas específicas do curso na ampliação do seu entendimento sobre a estruturação e progressão dos conteúdos, como o treinamento esportivo, a iniciação esportiva e também a atividade de monitoria universitária que realizou durante o curso. Porém, mantém o mesmo entendimento da primeira etapa do estudo, na qual a técnica deve ser priorizada, em especial o passe, à medida que favorece o jogo em conjunto, como se verifica a seguir:

"Como o futsal é um esporte mais coletivo, eu trabalharia mais as questões primeiramente de coletividade em si, trabalhando o passe junto. Porque na minha concepção o passe é o fundamento mais importante que tem no futebol, no esporte coletivo em geral. Justamente por ser um esporte coletivo, então trabalharia mais no foco dessa questão do passe mesmo, domínio de bola, condução de bola, para depois começar a focar mais no drible e chute" (S1).

O sujeito S2 considera que o seu estágio atual de "conhecimento" e de "experiência", permite vislumbrar outras formas de exercitação que possibilitem uma aprendizagem mais "dinâmica" do futebol, por meio de situações de jogo. Seu repertório de tarefas de aprendizagem parece ter se ampliado ao longo do curso, assim como seu discernimento sobre as situações mais adequadas para utilizá-las. No seu entendimento atual, as tarefas sintéticas também são alternativas para ensinar a técnica, mesmo que isso implique em uma aprendizagem mais lenta, à medida que ele é ensinado em conjunto com outros conteúdos. Questionado a respeito das estratégias, ele descreve algumas de suas novas possibilidades práticas:

“Eu poderia fazer composição, ataque contra defesa, só um lance. Vai com a bola, faz o toque, condução e pode chegar e chutar só no ataque, por exemplo. Três 
contra três, e depois quem tá atacando já fica na defesa, quem está na defesa já saí... um pouco mais dinâmico [...]" (S2).

Para S2, a técnica se mantém como conteúdo importante, indicando as disciplinas esportivas do currículo do curso de Educação Física como suas principais fontes de confirmação das crenças. Porém os conteúdos relativos à tática de jogo também passam a ser citados, segundo ele: "[...] tem vários outros que eu poderia ter ensinado, como tática, posicionamento, defesa, o ataque. Tem outros [...]". A sequência dos conteúdos adotada na primeira etapa da pesquisa por S2 mostra alteração no seu entendimento. Se naquela oportunidade não encontrou argumentos para justificar a forma como estruturou os conteúdos, nesta segunda etapa da pesquisa, ele indica que a sua decisão envolve circunstâncias pedagógicas diversas, dependente, portanto, dos "objetivos" traçados para cada aula ou treino.

Ao observar as imagens da sua aula gravada, S3 indica que acrescentaria várias mudanças na sua forma atual de ensinar. Segundo ele, a seleção da estratégia mais adequada depende da idade, do número de alunos, do nível de prática e nível de motivação. No início do curso, suas preocupações eram simplificar ao máximo a aprendizagem do basquetebol através de conceitos analíticos para "separar as partes do jogo". Na atualidade sua preocupação se volta mais ao uso das formas jogadas e das estruturas do jogo.

\footnotetext{
“Hoje eu mantenho uma sequência do exercício, uma evolução, uma progressão que a gente vai tendo até chegar perto do jogo. Também depende um pouco às vezes como você trabalha em geral assim, no plano do treino é uma sequência até chegar ao jogo ou, é que a gente vai evoluindo primeiro, coloca um contra um, depois dois contra dois, coloca três contra três" (S3).
}

Ao ser questionado sobre a ênfase que atribuiu ao ensino da técnica, na primeira etapa do estudo, S3 mantém o seu entendimento a respeito da importância deste conteúdo durante o processo de iniciação esportiva, acrescentando preocupações atuais a respeito do desenvolvimento de habilidades motoras básicas ("saltar", "pular", "correr", "mudar de direção"), a importância desses elementos para aprendizagens posteriores das técnicas do esporte, e ainda, o caráter lúdico e o ensino dos fundamentos de forma combinada. Os cursos de formação de curta duração foram suas principais fontes para estruturar os conteúdos de suas aulas no projeto de extensão universitário, no qual atuou durante alguns semestres.

\footnotetext{
"Mas eu acho que eu faria o mesmo, talvez drible e bandeja, hoje eu trabalho bastante quando eu trabalho bandeja, drible e arremesso junto, até trabalho os três porque o drible eu posso usar para a bandeja, e o arremesso então... os fundamentos eu trabalharia igual, só mudaria a dinâmica" (S3).
}

Na segunda etapa do estudo, constatou-se que S4 apresentou preocupações semeIhantes à primeira etapa do estudo, especificamente a necessidade do aperfeiçoamento da técnica para a prática do voleibol. Diferentemente das tarefas da primeira etapa, na 
atualidade, ele indica que adotaria tarefas de aprendizagem "menos analíticas", privilegiando as atividades "em grupo", semelhantes às situações de jogo, como se verifica no excerto a seguir:

\begin{abstract}
“Para o pessoal mais jovem eu não fragmentaria tanto dessa maneira, eu traria menores jogos (pequenos jogos) com eles, eu separaria a quadra, por exemplo, em dois lados, deixaria grupos, separaria em quatro grupos pra fazer pequenos jogos. [...] Só ataque, só defesa, fazendo eles passarem por todas os três fundamentos, isso tem muito mais efeito e eu faria dessa maneira" (S4).
\end{abstract}

Ao ser indagado sobre os conteúdos abordados na primeira etapa da pesquisa, S4 ratifica a sua crença a respeito da importância da técnica para o voleibol. Porém, na atualidade, ele considera que outros conteúdos devem estar associados simultaneamente ao ensino da técnica, de modo que a priorização de um conteúdo não implica, necessariamente, no seu isolamento, como ele mesmo afirma: "[...] com relação aos conteúdos o foco no voleibol é específico: o ataque, o toque, e no caso da defesa, a manchete ou toque. E esses conteúdos eu não poderia mudar, eu teria que enfatizá-los, mas eu mudaria a maneira que eu abordaria [...]". Suas fontes principais ainda são as observações da prática de outros treinadores mais experientes, sem deixar de indicar a contribuição da universidade. Assim, no entendimento de S4, uma sequência de conteúdos que proporcione melhorias gradativas no nível de aprendizagem dos alunos, deve levar em conta o nível de habilidade dos alunos, o planejamento anual estabelecido, a idade dos alunos e o período de competição.

Desde o início da pesquisa, S5 mostrou um repertório amplo de tarefas de aprendizagem, fruto de sua experiência pessoal de prática. S5 indica que na atualidade adotararia procedimentos semelhantes aos da primeira etapa, à medida que suas crenças iniciais foram confirmadas através de experiências durante a formação. Ainda mais, mantém o seu entendimento de que sua rotina de ensino, dentre as quais as tarefas analíticas são as mais ajustadas para alcançar o aprimoramento individual inerente ao voleibol. Suas principais fontes e, que ratificam suas cenças, são portanto, as disciplinas esportivas ligadas aos esportes coletivos e em especial àquela voltada ao esporte que ensinou, como ela mesma afirma: "[...] Eu acredito que não mudaria muito a sequência do simples para o complexo, porque se continua fazendo hoje, eu vi em disciplina, eu vi em estágio, eu vi a mesma sequência $[. . .]^{\prime \prime}$.

Com relação aos conteúdos, S5 mantém o mesmo entendimento da primeira etapa da pesquisa, na qual o domínio e precisão dos gestos técnicos são essenciais para a prática do esporte. Sua proposta atual seria de preparar seções para ensinar cada fundamento técnico especificamente. Manteria inclusive, sua rotina de atividades, que corresponde ao uso de tarefas analíticas, seguidas pelas sintéticas, para melhorar o "volume de jogo" e, a seguir o jogo formal para melhorar o que ela denomina de "comunicação entre os jogadores". Questionada a respeito da rotina de ensino que adotou, ela pondera: 


\begin{abstract}
“Não, não começaria pelo jogo, eu começaria do separado e iria para o global, da mesma forma, até porque, quando se tem o global fica mais disperso, a atenção já não é tão grande. Isso é o que eu priorizo nas minhas atividades, mas não quer dizer que eu não possa começar um aquecimento, por exemplo, jogando futebol, não tem problema nenhum. Mas uma hora eu vou ter que, da mesma forma que eu to promovendo esse social lá no final, lá no início vou ter que priorizar que a pessoa trabalhe por ela, vai chegar a bola, vai vir a bola e a pessoa vai ter que estar preparada pra vir e fazer aquilo, para que o time continue fazendo o resto da jogada" (S5).
\end{abstract}

Destaca-se que os sujeitos (S1, S2, S3, S4 e S5) mantiveram a crença de que as tarefas de aprendizagem analíticas são úteis para o ensino da técnica, ao declararem que a fragmentação cria as situações mais elementares de exercitação, facilitando a aprendizagem. Constatou-se também, que os sujeitos mantiveram a crença de que as tarefas sintética e global são importantes para aumentar o nível de motivação dos alunos. Ainda, no caso de S1 e S4, eles mantiveram suas crenças do início do curso, ao declararem o valor das tarefas sintéticas para o ensino da tática. No caso de S5, ela manteve sua crença inicial de que o ensino do voleibol tem uma sequência típica e reconhecidamente adequada de tarefas, que deve ser mantida, como segue: analítica/técnica, sintética/tática e global/jogar. Por outro lado, (S1, S2, S3 e S4) indicaram um novo entendimento sobre o uso das tarefas sintéticas, no sentido de reconhecer novas possibilidades de utilização e favorecer formas jogadas de aprendizagem, indicando inclusive, que privilegiariam este tipo de tarefa na sua rotina de ensino. No caso de S2, ele utilizaria tarefas sintéticas para ensinar a técnica, integrando outros conteúdos na aprendizagem esportiva, diferentemente do passado, quando este tipo de tarefa servia apenas para o lazer. Para S3, as formas jogadas também deixaram de ser apenas formas de diversão e assumem um papel pedagógico importante no ensino da tática.

Com relação aos conteúdos constatou-se, portanto, que S1, S3 e S5 mantiveram a crença de que a técnica é o elemento essencial e prioritártio em um processo de iniciação esportiva. Por outro lado, S2 alterou suas crenças e na atualidade ele acredita que a prioridade entre os conteúdos deve ser ponderada pelo professor para atender objetivos específicos de uma intervenção pedagógica, citando como exemplo, a necessidade de um desenvolvimento motor adequado dos jovens. A alteração que S4 faria, na atualidade, seria de promover a aprendizagem simultânea, integrando outros conteúdos esportivos durante um processo de iniciação.

Questionados a respeito das fontes para as mudanças, os graduandos indicaram uma variedade de experiências ocorridas ao longo do curso, tanto para as estratégias quanto para os conteúdos. Especificamente, aprendizagens de caráter "teórico-prático" nas disciplinas do curso, em particular aquelas específicas ao ensino dos esportes coletivos. Os livros, material didático, participação em eventos, participação em projetos de monitoria, projetos de extensão, estágios curriculares, criação individual de novos conhecimentos, compõem um conjunto de fontes formais e não formais de aprendizagem profissional para os graduandos. Destaca-se nos resultados sobre as fontes, a referência enfática de todos eles quanto à contribuição das experiências pessoais de prática de ensino durante o curso. 
Em particular, a prática de ensino do futebol em projeto de extensão universitária (S1) e basquetebol (S3); ensino do futebol no estágio curricular em esportes (S2); experiência de prática como treinador, após a segunda metade do curso (S4). O sujeito 5, não se referiu às experiências de prática de ensino.

De modo geral, as crenças prévias e, que se mantiveram ao final do curso, foram as seguintes: preocupação com a motivação dos alunos; as tarefas analíticas facilitam o ensino da técnica; as tarefas sintéticas motivam; as tarefas sintéticas servem ao ensino da tática; a técnica é essencial na aprendizagem esportiva. De fato, as pesquisas no âmbito da formação profissional em Educação Física têm destacado a dificuldade para se alterar as crenças prévias de universitários durante a formação (TSANGARIDOU, 2006).

Pesquisas qualitativas realizadas por Doolitle, Dodds e Placek (1993), com três universitários egressos, a respeito dos propósitos e de como se realiza um bom ensino, já demostravam que eles aceitaram práticas pedagógicas que complementaram as suas crenças iniciais e ignoraram outras que não se ajustavam à elas. Também, Matanin e Collier (2003), pesquisaram três futuros professores, após quatro anos de curso, mostrando que as habilidades motoras se mantiveram como conteúdos prioritários para o ensino da Educação Fisica escolar. Os autores destacam a importância de professores formadores conhecerem a biografia de universitários ingressantes para promover experiências de práticas de ensino que sejam semelhantes às experiências prévias, dando significado às suas novas aprendizagens. Ainda mais, Tsangaridou (2008), pesquisou dois universitários (futuros professores generalistas), ao final de um curso em metodologias de ensino em Educação Fisica, confirmando que a crença na prioridade das habilidades motoras se manteve inalterada. A autora sugere que programas de formação de professores incorporem atividades sistemáticas de reflexão em suas estruturas curriculares, para que universitários confrontem suas próprias crenças sobe o ensino. Também, Bernsteisn, Herman e Lysniak (2013), realizaram pesquisa com 10 universitários (futuros professores generalistas), em curso de metodologia de ensino de Educação Fisica, mostrando que algumas crenças obtidas em esporte competitivo se mantiveram e foram reforçadas durante o curso. Embora, alguns conhecimentos tivessem sido assimilados, a prioridade ao ensino das habilidades motoras e a uniformidade nos procedimentos de instrução são procedimentos que não se alteraram ao fim do curso. Para os autores é preciso pesquisar como as crenças se modificam durante os cursos formais de formação.

Para Richardson (2003), existem fortes evidências de que os universitários ingressam em cursos de formação de professores com um conjunto de crenças centrais, mais estáveis, difíceis de serem alteradas durante o curso, condicionando grande parte da aprendizagem profissional. Em parte, devido ao reduzido tempo de duração destes cursos e, em outra parte, devido à natureza dos conhecimentos e experiências disponíveis, seja nos contextos formais da universidade, ou na informalidade da vida cotidiana. A dificuldade, portanto, é que muitas das crenças prévias têm caráter tácito, procedimental, sendo mais significativas e obtidas a partir de experiências de prática pessoal na infância ao longo de pelo menos 10 anos, enquanto os cursos de graduação duram em média 3 a 4 anos, e privilegiam conhecimentos teóricos ou conceituais na maior parte do curso. Neste estudo, constatou-se 
que as experiências prévias condicionaram algumas das escolhas dos sujeitos. Assim, as suas experiências de ensino em estágios, monitoria, atividades de extensão, estiveram voltadas para as mesmas modalidades esportivas nas quais eles já possuíam experiências de prática pessoal.

É preciso, portanto, que a formação inicial considere a aprendizagem do professor como um processo contínuo de construção e reconstrução de conhecimentos e crenças, para tratar de conteúdos teóricos ou conceituais, mas especialmente do seu caráter procedimental, contemplando e sendo compatível com a natureza prática do conhecimento didático do professor. Para Cochran-Smith e Litle (1999) e Shulman (1987), o conhecimento didático reflete a mistura de um conjunto de conhecimentos formais e crenças pessoais, que se constituem na prática e a partir da própria reflexão do professor sobre a sua ação pedagógica. A natureza situada e, ao mesmo tempo personalizada deste conhecimento, remete ao entendimento de que a aprendizagem de como fazer decorre de um processo simultâneo de ação e construção das próprias crenças e conhecimentos. Ou seja, aprende-se melhor, quando se faz e, sobretudo, quando se compreende o que se faz. Nesta perspectiva, o professor em formação deve ser um elemento ativo na condução da sua aprendizagem, tendo a reflexão como um elo de ligação entre as crenças e os novos conhecimentos, transformando e dando significado às experiências (TSANGARIDOU; POLEMITOU, 2015).

De fato, a reflexão pode ser caracterizada como um processo individual de pensamento consciente, ordenado e coerente, na qual se busca estabelecer relações específicas entre alguma experiência e, as consequências que dessa ação resulta. As pessoas, quando refletem e interpretam os resultados positivos de suas ações, tendem a criar crenças duradouras sobre suas capacidades. São repertórios de êxito que permanecem armazenados na memória, podendo ser evocados à medida que episódios ou situações futuras, semelhantes ao passado, ocorram (SCHON, 2000).

Por outro lado, os sujeitos deste estudo que se apresenta, não indicaram a existência de procedimentos organizados para orientar os processos reflexivos, de forma sistemática e contínua, pelos professores formadores. Segundo Crawford, O’Reilly e Luttrell (2012), a ausência de estruturas válidas para auxiliar um processo de reflexão das experiências dos professores em formação, poderá implicar na mera reprodução de práticas pedagógicas, muitas vezes incipientes ou pouco válidas, ou ainda na perda do potencial das experiências prévias dos universitários em favor de uma aprendizagem mais significativa e consistente ao longo de toda a carreira profissional. Nesta perspectiva, McCollum (2002) propôs um quadro de referência para a análise da reflexão de professores de Educação Fisica em formação, para aprofundar o pensamento reflexivo de professores; ampliar o âmbito da reflexão à múltiplos aspectos do ensino; orientar o professor a criar seu próprio conhecimento profissional; confrontar suas próprias crenças e possibilidades de intervenção pedagógica; conectar conhecimentos teóricos e práticos; entre outras.

Neste estudo, os resultados mostraram que todos os sujeitos declararam a aprendizagem de novos conhecimentos ou confirmaram suas crenças prévias a partir de disciplinas do curso. Reconhecendo igualmente, que as mudanças foram decorrentes, 
simultaneamente, de um processo amplo e prolongado de aprendizagens e de alguma maturidade pessoal ocorrida durante o curso. Por outro lado, eles indicaram que as principais mudanças ocorridas nas suas crenças, estiveram ligadas diretamente às situações de prática de ensino dentro do contexto universitário, particularemente, projetos de extensão (S1 e $\mathrm{S} 2$ ), projeto de monitoria (S3) e atuação como treinador esportivo (S4). O ponto comum nestes resultados, diz respeito à importância da experiência na construção do conhecimento sobre o ensino. Assim, destaca-se que as experiências diretas de prática no ensino se mantiveram, em grande parte, como referenciadoras de aprendizagem profissional, ou como sugere Navarro (2012), estas são ainda as fontes com maior poder para influenciar na construção de crenças para o ensino, à medida que fornecem referências reais e objetivos de realização e sucesso.

Pesquisa realizada sobre as mudanças das crenças prévias através da análise de metáforas por Tannehill e Macphail (2014), mostrou que o entendimento dos graduandos de Educação Física sobre o ensino e aprendizagem se alteraram, passando de uma concepção centrada no professor para o reconhecimento do aluno como centro do processo de aprendizagem. De modo semelhante, Ní Chróinín e O’Sullivan (2016) investigaram 59 professores em três momentos diferentes da formação de professores generalistas, para examinar as crenças sobre como aprender a ensinar Educação Física. Os achados indicaram que o programa de formação apoiou involuntariamente as crenças dos investigados para ensinar os conteúdos da Educação Física através do desenvolvimento de novas ideias de atividades. Ainda mais, pesquisa realizada por Philpot e Smith (2011), com 12 graduandos em Educação Física, mostraram mudanças ao fim do curso, porém os autores sugerem que a falta de um processo sistemático de reflexão provocaram apenas mudanças superficiais nas crenças dos graduandos. Neste estudo que se apresenta e, considerando as limitações já citadas, acredita-se que o curso de graduação contribuiu para reforçar aos sujeitos (S1, S2, S3 e S4) as suas crenças iniciais de que a motivação é essencial para o engajamento dos alunos. Porém, no início do curso, a preocupação dos sujeitos estava baseada na sua própria motivação para a prática pessoal e, ao fim do curso, eles mostraram preocupações sobre os aprendizes e de como a aprendizagaem deve ocorrer, fazendo referência às informações e aos conhecimentos obtidos nas disciplinas do curso. Acredita-se que este é um indício do surgimento de preocupações pedagógicas baseadas em conceitos assimilados ao longo do curso, de que os aprendizes estão na centralidade do processo de aprendizagem, necessitando portanto, de estudos mais sistematizados de acompanhamento dos procedimentos pedagógicos adotados no contexto ou ambiente da formação do professor.

\section{CONCLUSÕES}

A análise dos resultados permite afirmar que grande parte das crenças dos universitários, obtidas antes de ingressarem na universidade, mantiveram-se estáveis ao final do curso e condicionaram algumas experiências de aprendizagem. Estas crenças mais centrais na estrutura de pensamento dos sujeitos, influenciaram na percepção e seleção de novas 
experiências de aprendizagem ao longo do curso, de modo que as práticas pessoais na infância, em um esporte especifico, direcionaram a busca de práticas de ensino para o mesmo tipo de esporte. Há, portanto, um potencial nas experiências pessoais de prática esportiva ou motoras, obtidas antes da universidade, para fornecer alguma segurança pessoal e atribuir significado a novas situações de aprendizagem.

Especificamente para este estudo, as crenças que se mantiveram foram: as tarefas analíticas servem ao ensino da técnica; a aula deve ser motivadora; as tarefas sintéticas e global são divertidas; as tarefas sintéticas servem ao ensino da tática; os conteúdos motores ou técnicos são essenciais à aprendizagem esportiva. De fato, estes procedimentos de ensino possuem respaldo na literatura especializada. Além disso, as disciplinas de caráter teórico-prático do currículo contribuíram para reforçar as crenças prévias e promover algumas mudanças conceituais no entendimento dos sujeitos, relativamente à busca de uma prática mais global e centrada no aluno.

Mesmo que os sujeitos reconheçam a contribuição do curso de graduação, na construção dos seus conhecimentos sobre o ensino, destaca-se que há um debate constante no contexto universitário, sob o ponto de vista conceitual e dos diversos modelos e metodologias de ensino, elaboradas nas ultimas décadas. Estes debates, portanto, permitiriam supor uma interferência conceitual maior da universidade na forma como os sujeitos deste estudo interpretaram os seus procedimentos utilizados nesta ultima fase da pesquisa.

As experiências de práticas de ensino promovidas pela universidade, particularmente, projetos de monitoria, estágio, extensão, foram destacadas pelos sujeitos enquanto situações que favoreceram o engajamento pessoal e a aprendizagem para o ensino, pois estavam ligados aos esportes na qual possuíam experiências de prática pessoal prévia. Estes resultados, evidenciam, por um lado, a importância das experiências diretas de intervenção pedagógica para a construção do conhecimento sobre o ensino e, por outro lado, a natureza procedimental dos conhecimentos que os sujeitos possuem ao final do curso.

Embora as oportunidades de práticas de ensino na universidade tenham contribuído para a obtenção de novos conhecimentos para o ensino dos esportes, os sujeitos não mencionaram a existência de situações sistematizadas e continuas de reflexão que favorecessem esse processo de reconstrução individual das crenças, conforme tem sugerido a literatura especializada. Assim, é preciso considerar a formação inicial como uma etapa de reconstrução da crenças pessoais, considerando sobretudo, o processo de construção da identidade profissional. De fato, isso aponta para uma possibilidade de realização de investigações longitudinais sobre a participação e o engajamento dos universitários durante a formação inicial.

\section{REFERÊNCIAS}

ABELSON, R. P. Differences between belief system and knowledge system. Cognitive Science, v. 3, p. 355-366, 1979. 
julho/2018

ADAMAKIS, M.; ZOUNHIA, K. The impact of occupational socialization on Physical Education pre-service teachers' belief about four important curricular outcomes: a crosssectional study. European Physical Education Review, v. 22, n. 3, p. 279-297, 2016.

ALVES F, C. A triangulação enquanto técnica de validação qualitativa. Revista Portuguesa de Pedagogia, Coimbra, v. 36, n.1, p. 77-87, 2002.

ALVES-MAZZOTTI, A. J.; GEWANDSZNAJDER, F. O método nas ciências naturais e sociais: pesquisa quantitativa e qualitativa. São Paulo: Pioneira Thompson Learning, 2004.

BARDIN, L. Análise de conteúdo. Ed. rev. e actual. Lisboa: Edições 70, 2010.

BEHETS, D.; VERGAUWEN, L. Learning to teach in the field. In: KIRK, David; MACDONALD, D.; O'SULLIVAN, M. (Eds.). Handbook of Physical Education. London: Sage, 2006. p. 407-424.

BERNSTEIN, E.; HERMAN, A. M.; LYSNIAK, U. Beliefs of pre-service teachers toward competitive activities and the effect on implementation and planning for Physical Education classes. Teacher Education Quarterly, San Francisco, v. 40, n. 4, p. 63-79, 2013.

COCHRAN-SMITH, M.; LYTLE, S. L. The teacher research movement: a decade later. Educational Researcher, Washington, v. 28, n. 7, 15-25, 1999.

CRAWFORD, S.; O'REILLY, R.; LUTTRELL, S. Assessing the effects of integrating the reflective framework for teaching in physical education (RFTPE) on the teaching and learning of undergraduate sport studies and physical education students. Reflective Practice, v. 13, n. 1, 115-129, 2012.

DENZIN, N. K.; LINCOLN, Y. S. O planejamento da pesquisa qualitativa: teorias e abordagens. 2. ed. Porto Alegre: Artmed, 2008.

DOOLITTLE A, S.; DODDS, P.; PLACEK, J. H. Persistence of beliefs about teaching during formal training of preservice teachers. Journal Teaching in Physical Education, v. 12, p. 355-365, 1993.

FIVES, H.; BUEHL, M. M. Spring cleaning for the messy construct of teachers' beliefs: What are they? Which have been examined? What can they tell us? In: HARRIS, K. R.; GRAHAM, S.; URDAN, T. (Orgs.). APA Educational Psychology Handbook. 2. ed. Washington DC: APA, 2012. p. 471-499.

GROSSMAN, P.L. The making of a teacher: teacher knowledge and teacher education. New York: Teachers College Press, 1990.

KULINNA, P. H.; BRUSSEAU, T.; FERRY, M.; COTHRAN, D. Preservice teachers' belief systems towards curricular outcomes for Physical Education. Research Quarterly for Exercise and Sport, Abingdon, v. 81, n. 2, p. 189-198, 2010.

MATANIN, M.; COLLIER, C. Longitudinal analysis of preservice teachers' beliefs about teaching physical education. Journal Teaching in Physical Education, v. 22, n. 2, p.153-168, 2003.

MCCOLLUM, S. The reflective framework for teaching in physical education: a pedagogical tool. Journal of Physical Education, Recreation \& Dance, v. 73, n. 6, p. 39-42, 2002. NAVARRO, L. P. Autoeficacia del profesor universitario: eficacia percibida y práctica docente. Madrid: Narcea S. A. de Ediciones, 2012. 
NÍ CHRÓINÍN, D.; O'SULLIVAN, M. Elementary classroom teachers' beliefs across time: learning to teach Physical Education. Journal of Teaching in Physical Education, v. 35, p. 97-106, 2016.

PHILPOT, R.; SMITH, W. Beginning and graduating student-teachers' beliefs about physical education: a case study. Asia-Pacific Journal of Health, Sport and Physical Education, v. 2, n. 1, p. 33-50, 2011.

RAMOS, V.; SOUZA, J. R.; BRASIL, V. Z.; BARROS, T. E. S.; NASCIMENTO, J. V. As crenças sobre o ensino dos esportes na formação inicial em Educação Física. Revista da Educação Física/UEM, v. 25, n. 2, p. 231-244, 2014.

RANDALL, L.; MAEDA, J. K. Pre-service elementary generalist teachers' past experiences in elementary Physical Education and influence of these experiences on current beliefs. Brock University, St. Catharines, v. 19, n. 2, p. 20-35, 2010.

RICHARDSON, V. Preservice teachers' beliefs. In: RATHS, J.; MCANINCH, A. (Orgs.). Teacher belief and classroom performance: the impact of teacher education. Greenwich, CT: Information Age Publishers, 2003. p. 1-22.

RINK, J. Teaching physical education for learning. St. Louis: Mosby, 1993.

SCHÖN, D. Educando o profissional reflexivo: um novo design para o ensino e a aprendizagem. Porto Alegre, Artmed, 2000.

SHULMAN, L. Knowledge and teaching: foundations of a new reform. Harvard Educational Review, v.57, n.1, 1987.

SOFO, S.; BEARD, D. H.; SLATTERY, A.; HOWARD, S. Preservice teachers' beliefs about the curricular goals for physical education. Missouri Journal Health, Physical Education, Recreation, and Dance, Reston, v. 22, n. 1, p. 18-35, 2012.

TANNEHILL, D.; MACPHAIL, A. What examining teaching metaphors tells us about preservice teachers' developing beliefs about teaching and learning. Physical Education and Sport Pedagogy, v. 19, n. 2, p. 149-163, 2014.

TICÓ-CAMÍ, J. Tareas deportivas en los deportes colectivos: Una aplicación al baloncesto. In: IBAÑEZ-GODOY, S.; MACÍAS-GARCÍA, M. (Orgs.). Novos horizontes para o treino do basquetebol, Cruz Quebrada: Faculdade de Motricidade Humana, Universidade Técnica de Lisboa, p. 87-110, 2002.

TSANGARIDOU, N. Teachers' beliefs. In: KIRK, D.; MACDONALD, D.; O'SULLIVAN, M. (Orgs.). The handbook of physical education. London: SAGE, 2006. p. 486-501.

TSANGARIDOU, N. Trainee primary teachers' beliefs and practices about physical education during student training. Physical Education and Sport Pedagogy, v. 13, n. 2, p. 131-152, 2008.

TSANGARIDOU, N.; POLEMITOU, I. Exploring pre-service classroom teachers' reflections on teaching physical education. European Physical Education Review, v. 2, n. 1, p. 66-82, 2015. 